\title{
Examination of Effects of Regular Sports Training on Individual Skills in Trainable Children with Autism
}

\author{
Murat AKYÜZ \\ Celal Bayar University, Manisa, Turkey \\ Cansu ODABAŞ \\ Bartın University, Bartın, Turkey \\ Öznur AKYÜZ \\ Celal Bayar University, Manisa, Turkey
}

\author{
Yeliz DOĞRU \\ Ege University, İzmir, Turkey \\ Ömer ŞENEL \\ Gazi University, Ankara, Turkey \\ Murat TAŞ, Tolga BEŞİKÇI \\ Celal Bayar University, Manisa, Turkey
}

\begin{abstract}
The aim of this study is to examine the effects of regular sport training implemented at Integrated Disabled Athlete Department on autistic children's adolescence development of individual abilities as motor proficiencies. The subject group of this study is composed of 12 boys with autism who practiced physical education programs in running speed and agility, balance, coordination, and strength for 13 weeks. They were trained for one hour a day and for three days a week. In order to analyse the result of that training program, both preliminary and post-test techniques and particularly Bruininks-Oseretsky Test of Motor (2nd ed.) (BOT-2) were implemented. The result of preliminary and post-tests showed that there is a significant difference between motor levels (running speed and agility, balance, coordination, and strength). This result was interpreted that physical education has positive effects on the subjects. As a result, regular sports training provided to children with autism were found to promote the development of physical properties.
\end{abstract}

Keywords: autism, basic sports education, physical development

\section{Introduction}

Although autism is the organic damage occurring in brain, it is a disease which causes the individual to interpret events differently and to behave unusually (Güneş, 2005; Crawford, MacDonncha, \& Smyth, 2013). Autism is recognized with various symptoms. Social interaction, communication disorders, failure to focus (Aydin, 2013), and repeating actions (Filipek et al., 1999) are the primary characteristics. While symptoms of autism vary in itself, no connection can be established between autism and the personality traits of persons that constitute symptoms of violence towards themselves or the people around (London, 2007).

Main characteristics of the Autism Spectrum Disorder (ASD) are social interaction disorders, communication disorders, limited attention, and repetitive behaviour. Psychomotor development is the process of regulation of

Murat AKYÜZ, Ph.D, associate professor, Faculty of Sport Sciences, Celal Bayar University.

Cansu ODABAŞ, Ph.D. candidate, student, Institute of Health Sciences, Bartın University.

Öznur AKYÜZ, Ph.D, assistant professor, Faculty of Sport Sciences, Celal Bayar University.

Yeliz DOĞRU, Ph.D. candidate, student, Institute of Health Sciences, Ege University.

Ömer ŞENEL, Ph.D., professor, Faculty of Sport Sciences, Gazi University.

Murat TAŞ, Ph.D, associate professor, Faculty of Sport Sciences, Celal Bayar University.

Tolga BEŞİKÇI, Ph.D. candidate, research assistant, Faculty of Sport Sciences, Celal Bayar University. 
the movements in life-long motor skills. These skills appear with cooperation of the mind, hearing organs, and muscles (Filipek et al., 1999). Psychomotor properties of individuals with autism, such as walking, flexibility, and balance develop late. Although there are no differences in physically normal children with autism compared to their age group, implementation of certain skills can delay even if they are expected to perform various skills and actions in time. Children with ASD can experience problem in the process of adaptation to the structure of action. For instance, deficiencies are observed in fine motor skills, such as painting a certain area or throwing balls inside a basket. Such problems are associated with coordination problems (Berninger \& Rutberg, 1992).

It is not easy for individuals with ASD to join physical activity, since they have insufficient motor function, insufficient motivation, and self-control difficulty. It can be a matter of the fact that such individuals have difficulty in adapting to team sports, such as basketball and complex sport branches, for example, archery, which requires physical and motor skills. Rather than the aforesaid branches, these individuals prefer activities that do not include social interaction (Todd \& Reid, 2006). Various purposes can lead to measurement of motor skills in children with autism, such as detecting the difference between the age-appropriate performance and current performance, creating individual training program to improve motor development, and helping explain the detected reasons for motor deficiency with the deficiencies in other areas of development. Many tests have been developed to evaluate the motor skills of children with autism as well as children with other special needs. One of these tests, Bruininks-Oseretsky Test of Motor (2nd ed.) (BOT-2) is individual, and of norm-reference. It evaluates gross and fine motor skills and is used in individuals aged 4-21. BOT-2 is conducted in three areas and includes eight sub-tests (Bruininks, 2005).

The ability of people affected by deficiency to sustain life without being dependent on others and to meet their own needs will significantly affect their self-perception. Equal opportunities provided will make sure that individuals affected by deficiency participate more in social life. On the other hand, changes can occur in the attitude of the other individuals in society towards them, once they see that they can function independently in society. This will facilitate social acceptance. Handicapped individuals taking part in sport activities will participate in social life and develop positive self-esteem. In this study, it is aimed to both provide contribution to the literature and increase awareness on development of socially deficient individuals by detecting skill developments, which occur as a result of regular sport training.

\section{Literature Review}

Diagnostic characteristics of autism include difficulty in social interaction, delay in communicational skills, and limiting patterns in specific development and behaviours or actions (American Psychiatric Association [APA], 2000). In addition to such reasons, regression in development of motor skills in individuals with autism is detected. In a study performed on 101 children with autism, Green et al. (2008) found out that 70\% of these children had certain movement disorder. According to the results of this research, disorder in motor skills of individuals with autism limits or reduces their physical activities. When Pan (2008) compared primary education students with ASD $(n=23)$ and without handicap $(n=23)$ in terms of their levels of physical activity in school period, it was seen that children with autism were significantly less active. Lang et al. conducted a study in 2010 and stated that exercise works showed positive developments on motor skills of individuals with ASD and that exercise was a very important requirement in lives of such individuals (Lang et al., 2010).

While autism brings change to behaviour, inefficiency at various rates is seen in motor skills. Apart from physiological and biological developments, motor development in children includes other areas of change as 
well (Haywood \& Getchell, 2005). Inefficiency considered within emotional frame can also create problems in motor behaviours at the same level (Piek \& Dyck, 2004). As of the body structure, interruptions in implementation of some movements may be encountered while they are required to perform various movements within ordinary time. In such children, exercise programs towards improvement of basic movement skills must be used at preparation stage of training programs. Movements gained provide contribution to communications of these children with the outer world (Eichstaedt \& Lavay, 1992). In a study they performed using the BOT-2 in 1998, Ghaziuddin and Butler (1998) found similar results in movements of individuals diagnosed with autism and Asperger Syndrome.

Almost half of the individuals with autism fail to display talking skill related to their basic needs (Noens, Van Berckelaer-Onnes, Verpoorten, \& Van Duijn, 2006). Differences in such skills can be seen after the age of one as delay of the period of talking meaningless words prior to preverbal period, and abnormal hand movements and behaviours. These characteristics have been observed to become less frequent and decrease in children with autism after the age of two and three. Children with autism often repeat the voices they hear (Landa, 2007; Tager-Flusberg \& Caronna, 2007). Attention deficit may easily distinguish children with autism from others, e.g. they may look at the hand which is used to show rather than at the location that is shown (Volkmar, Chawarska, \& Klin, 2005; Tager-Flusberg \& Caronna, 2007). In the studies performed, it was seen that adults with autism provided better results compared to the children with autism aged 8-15 in subjects of grammar, such as vocabulary and making sentence. Meaningless word, voice repetition, and out-of-purpose sentences are encountered in individuals with ASD. This may also include failure to grasp grammar, language, jokes, questions, and orders. In addition, such individuals tell events as if they were third person due to lack of pronoun in expressions, for instance, "he wants candy" (Williams, Goldstein, \& Minshew, 2006).

It was stated by Wolery, Bailey, and Sugai (1988) that errorless teaching methods could be implemented in cases where individuals failed to learn through accustomed methods. Researchers have stated that these methods are effective in teaching of single-step behaviours and behaviours as well as to the students of various handicap groups. It is known in researches conducted towards disadvantaged groups that a well programmed sport activity provides contribution to interaction with social environment as well as motor and physical development of handicapped individuals.

In light of this information, the aim of this study is to examine the effects of the regular sports training practised in the Integrated Disabled Athlete Support Unit on development of individual skills (motor proficiency) in children with autism, and provide contribution to the literature. The facts that children with autism have insufficient motor skills despite having the physical structure suitable for their ages, that exercises concerning such skills must be included in rehabilitation programs, and that exercises provide positive effect on development of these weak motor skills are encountered in literature studies. However, they are used usually limited to case reports.

\section{Method}

Below are the prerequisite skills required to be possessed by the children with autism who participated in this study: ability to fulfil the commands given, imitation skill, not giving unnecessary reaction to touching for the purposes of aid, not possessing another handicap, not having another health problem, and retention skill. Information on proficiencies of the children was obtained from their parents prior to the study in order to detect whether they have these prerequisite skills. Before starting to work with children with autism, meetings were 
first held with institutional managers, trainers, and families of the students, and information was provided about the study.

\section{Study Group}

The study included children aged 8-14, who participate in the TR51/14/SOSKA/0061 Integrated Disabled Athlete Support Unit project executed by Ankara Provincial Directorate of Youth and Sports, and are diagnosed with autism by psychiatrists, and who continue special training and rehabilitation centres (being in medical treatment process and not exercising regularly), and have the prerequisite skills defined below. Opinions of the special training expert charged at the unit as well as the psychologist were consulted in the selection of children with autism.

Boys with autism in the basic sports education branch, where the highest number of guidance to the unit is made by characteristics of individual among the 13 branches, took part in the study. Grouping was performed as homogeneously as possible within the frame of the limitations detected, and envisaged as a result of the preliminary performance tests conducted. An exercise group with autism (EGA) was determined composed of 12 boys with autism, who had the acceptance of criteria for the study.

\section{Data Collection Instruments}

Research was conducted in Öncü Ankara Integrated Disabled Athlete Support Unit in the performance measurement laboratory, which had the suitable ground, thermal, light, and sound insulation for the trainings and studies. Balance beam, step stand, balance wedges, plastic poles, referee's whistle, measuring tape, sphygmometer to measure rest and training heart rates, and chronometer were used during exercise implementations on children with ASD.

Running speed and agility, balance, bilateral coordination, and strength tests of the BOT-2 parameters were applied on the group in order to research the effect of 13 weeks' exercise program on motor proficiency levels of the children with autism in this study. Preliminary test data were processed on the information forms prepared in advance, and exercise program was prepared towards these tests.

Exercise training was applied on the children with autism for 60 minutes a day and three days a week for 13 weeks. BOT-2 Battery gross motor sub-test was used in the research in order to evaluate the motor proficiencies of the children with autism.

\section{BOT-2 of Motor Proficiency}

BOT-2 is developed to measure the motor proficiencies of children aged 4-21. It is the edited form of the first version developed by Bruininks-Oseretsky in 1978. BOT-2 is a tool used to help trainers, therapists, and researchers evaluate the motor proficiencies of individuals, prepare and analyse programs that can develop motor skills, and detect and evaluate various motor functional disorders and developmental regressions. Test tools are designed in a manner to make individuals focus, provide the possibility of implementation within standard pattern, and simplify practise and analysis (Bruininks, 2005).

BOT-2 is composed of eight sub-tests and 53 items. Each sub-test group contains various items that measure different skills. Of the eight sub-tests, four measure gross motor, one measure both fine and gross motor, and three measure fine motor proficiency (Bruininks, 2005; Mülazımoğlu-Ballı \& Gürsoy, 2012; Düger, Bumin, Uyanık, Ak1, \& Kayıhan, 1999). 
In our study, six sub-items used in the short form of four sub-tests related to gross motor of BOT-2 were used. Before starting the test, participants (EGA) were asked to throw a small ball given in their hands with the hand they preferred and to tap their feet, hand, and foot. Preferences were detected after three repetitions.

\section{Thirteen Weeks' Exercise Program of the Group}

Thirteen weeks' exercise program of children with autism and their contents are shown in Tables 1-2.

Table 1

(EGA) 13 Weeks' Exercise Program

\begin{tabular}{llll}
\hline & 0th-4th week & 4th-8th week & 8th-13th week \\
\hline Training duration & Warm-up: 15 minutes & Warm-up: 15 minutes & Warm-up: 15 minutes \\
\multirow{2}{*}{ Station workout } & Main half: 40 minutes & Main half: 40 minutes & Main half: 40 minutes \\
Total & Cool-down: 5 minutes & Cool-down: 5 minutes & Cool-down: 5 minutes \\
& 60 minutes & 60 minutes & 60 minutes \\
\hline
\end{tabular}

Table 2

(EGA) 13 Weeks' Exercise Sessions

\begin{tabular}{|l|l|l|}
\hline 0th-4th week exercise sessions & 4th-8th week exercise sessions & 8th-13th week exercise sessions \\
\hline $\begin{array}{l}\text { General warm-up: } 10 \text { minutes } \\
\text { Stretching exercise: } 5 \text { minutes }\end{array}$ & $\begin{array}{l}\text { General warm-up: } 10 \text { minutes } \\
\text { Stretching exercise: } 5 \text { minutes }\end{array}$ & $\begin{array}{l}\text { General warm-up: } 10 \text { minutes } \\
\text { Stretching exercise: } 5 \text { minutes }\end{array}$ \\
\hline Main half: Station workout 40 minutes & Main half: Station workout 40 minutes & Main half: Station workout 40 minutes \\
\hline $\begin{array}{l}\text { Cool-down: Resistless cool-down 5 } \\
\text { minutes }\end{array}$ & $\begin{array}{l}\text { Cool-down: Resistless cool-down 5 } \\
\text { minutes }\end{array}$ & $\begin{array}{l}\text { Cool-down: Resistless cool-down 5 } \\
\text { minutes }\end{array}$ \\
\hline
\end{tabular}

Station workouts are composed of walking exercises on the balance beam and balance wedges, passing barriers by jumping with both feet, stepping on and off step stands, standing on preferred foot on balance board, standing on balance beam with toe and heel contact, sub-test/bilateral coordination, simultaneous tapping of foot and hand fingers in the same direction, simultaneous tapping of foot and hand fingers in different directions, and sub-test/strength exercises.

\section{Data Collection}

Practitioners who took part in the research are composed of an assistant professor in Gazi University Special Education Unit, and four trainers, who graduated from the School of Physical Education and Sports of the same university, received on-the-job training prior to the study, and worked in Ankara Provincial Directorate of Youth and Sport. These trainers are provided training by the physiotherapist working in the Special Education and Rehabilitation Centre, and the assistant professor working in the Special Education Department on the exercise training, verbal and visual interaction in children with autism, and general characteristics of children with autism. The associate professor and the researcher, who took part as practitioners in hands-on training, performed preliminary study for one week in the Integrated Disabled Support Unit where the implementation was to be made.

\section{Data Analysis}

Analyses were conducted over point scores, since no study had been performed previously related to BOT-2 in Turkey and on Turkish children. Although the development in motor skill levels of the children is 
very low according to the scientific studies conducted, it is recommended to use point scores instead of norm values in order to observe this development (Mülazımoğlu-Ballı \& Gürsoy, 2012).

Statistical evaluation of data was performed using Statistical Package for the Social Sciences, version 20.0 (SPSS 20.0) statistical package program. Non-parametric Wilcoxon test was used for test scores, motor performance and physical conformity data, and in-group changes. $P<0.05$ value was selected as the level of significance for comparisons.

\section{Findings}

It was detected that children with autism, who were included in the study, had a mean age of $10.07 \pm 0.25$ years, mean body weight of $24.97 \pm 0.64$ kilograms $(\mathrm{kg})$, and mean height of $126.79 \pm 1.33$ centimetres $(\mathrm{cm})$.

Motor proficiency levels of the children in the group were evaluated with BOT-2. Six sub-tests of the four test related to gross motor were used in the evaluation, with BOT-2 parameters: running speed and agility, balance, bilateral coordination, and strength. Arithmetic mean and standard deviation values were calculated for each sub-test.

Twelve boys with autism in the study group scored $2.82 \pm 0.13$ points in running speed and agility test, $3.29 \pm 0.11$ points in standing on preferred foot on balance beam, $1.16 \pm 0.07$ points in standing on balance beam with toe and heel contact, $1.24 \pm 0.08$ points in simultaneous tapping of foot and hand fingers in the same direction, $0.82 \pm 0.09$ points in simultaneous tapping of foot and hand fingers in different directions, and $6.32 \pm$ 0.15 points in standing broad jump in the preliminary test (BOT-2). Motor proficiency results of the group are shown in Table 3.

Table 3

(EGA) Preliminary Test (BOT-2) Results

\begin{tabular}{|c|c|c|c|}
\hline \multirow{2}{*}{\multicolumn{2}{|c|}{ Tests }} & \multicolumn{2}{|c|}{$(\mathrm{O})$ Preliminary test $(n=12)($ BOT-2 $)$ point } \\
\hline & & \multirow{2}{*}{$\begin{array}{l}\bar{X} \\
2.82\end{array}$} & \multirow{2}{*}{$\begin{array}{l}\text { SS } \\
0.13\end{array}$} \\
\hline Running spee & and agility & & \\
\hline \multirow{2}{*}{ Balance } & Standing on preferred foot on balance beam & 3.29 & 0.11 \\
\hline & Standing on balance beam with toe and heel contact & 1.16 & 0.07 \\
\hline \multirow{2}{*}{$\begin{array}{l}\text { Bilateral } \\
\text { Coordination }\end{array}$} & Simultaneous tapping of hand and foot fingers in the same direction & 1.24 & 0.08 \\
\hline & Simultaneous tapping of hand and foot fingers in different directions & 0.82 & 0.09 \\
\hline Strength & Standing broad jump & 6.32 & 0.15 \\
\hline
\end{tabular}

Table 4

(EGA) Final Test (BOT-2) Results

\begin{tabular}{llll}
\hline \multirow{2}{*}{ Tests } & \multicolumn{2}{c}{ (S) Final test $(n=12)($ BOT-2) point } \\
\cline { 3 - 4 } & \multicolumn{1}{c}{ ss } \\
\hline Running speed and agility & 3.85 & 0.11 \\
\multirow{2}{*}{ Balance } & Standing on preferred foot on balance beam & 4.56 & 0.12 \\
& Standing on balance beam with toe and heel contact & 1.64 & 0.09 \\
Bilateral & Simultaneous tapping of hand and foot fingers in the same direction & 1.72 & 0.10 \\
coordination & Simultaneous tapping of hand and foot fingers in different directions & 1.19 & 0.09 \\
Strength & Standing broad jump & 8.83 & 0.20 \\
\hline
\end{tabular}

Twelve boys with autism in the study group scored $3.85 \pm 0.11$ points in running speed and agility test, $4.56 \pm 0.12$ points in standing on preferred foot on balance beam, $1.64 \pm 0.09$ points in standing on balance 
beam with toe and heel contact, $1.72 \pm 0.10$ points in simultaneous tapping of foot and hand fingers in the same direction, $1.19 \pm 0.09$ points in simultaneous tapping of foot and hand fingers in different directions, and $8.83 \pm$ 0.20 points in standing broad jump in the post-exercise of BOT-2 test. Gross motor proficiency values of the exercise group with autism were compared through the Wilcoxon paired two-sample test. When the results were examined, it was seen in all tests that exercise training provided a statistically significant difference. Comparison of the motor proficiency results of the group are shown in Table 4.

When the preliminary-final test difference of the EGA was examined, a difference of $1.03 \pm$ points occurred in running speed and agility test, a difference of $1.27 \pm$ points in standing on preferred foot on balance beam, a difference of $0.48 \pm$ points in standing on balance beam with toe and heel contact, a difference of 0.48 \pm points in simultaneous tapping of foot and hand fingers in the same direction, a difference of $0.37 \pm$ points in simultaneous tapping of foot and hand fingers in different directions, and a difference of $2.51 \pm$ points in standing broad jump.

Gross motor proficiency values of the exercise group with autism were compared through the Wilcoxon paired two-sample test. When the results were examined, it was seen in all tests that exercise training provided a statistically significant difference $(p<0.05)$ (see Table 5).

Table 5

(EGA) Preliminary Test-Final Test (BOT-2) Results

\begin{tabular}{|c|c|c|c|c|c|c|c|}
\hline \multirow{2}{*}{\multicolumn{2}{|c|}{$(\mathrm{EGA})(n=12)$ gross motor tests }} & \multicolumn{2}{|c|}{$\begin{array}{l}\text { Preliminary test } \\
\text { (BOT-2) point }\end{array}$} & \multicolumn{2}{|c|}{$\begin{array}{c}\text { Final test } \\
\text { (BOT-2) point }\end{array}$} & \multicolumn{2}{|c|}{$\begin{array}{l}\text { Wilcoxon paired } \\
\text { two sample test }\end{array}$} \\
\hline & & $\bar{X}$ & SS & $\bar{X}$ & ss & Z & $p$ \\
\hline \multicolumn{2}{|c|}{ Running speed and agility } & 2.82 & 0.13 & 3.85 & 0.11 & -3.072 & $0.002^{*}$ \\
\hline \multirow{2}{*}{ Balance } & Standing on preferred foot on balance beam & 3.29 & 0.11 & 4.56 & 0.12 & -3.066 & $0.002^{*}$ \\
\hline & Standing on balance beam with toe and heel contact & 1.16 & 0.07 & 1.64 & 0.09 & $-3,066$ & $0.002^{*}$ \\
\hline \multirow{2}{*}{$\begin{array}{l}\text { Bilateral } \\
\text { coordination }\end{array}$} & $\begin{array}{l}\text { Simultaneous tapping of hand and foot fingers in the } \\
\text { same direction }\end{array}$ & 1.24 & 0.08 & 1.72 & 0.10 & -3.063 & $0.002^{*}$ \\
\hline & $\begin{array}{l}\text { Simultaneous tapping of hand and foot fingers in } \\
\text { different directions }\end{array}$ & 0.82 & 0.09 & 1.19 & 0.09 & $-3,068$ & $0.002^{*}$ \\
\hline Strength & Standing broad jump & 6.32 & 0.15 & 8.83 & 0.20 & -3.061 & $0.002^{*}$ \\
\hline
\end{tabular}

Note. ${ }^{*} p<0.05$

\section{Discussion and Conclusion}

An evaluation group was formed in this study depending on the age groups and current skill levels in the basic sport training branch, in which the highest number of children and youth with autism was present, in order to detect the effect of 13 weeks' training program on the motor proficiency levels of children with autism. Twelve boys with autism participated in the study voluntarily as a result of taking age, preliminary performance status, and skill levels as basis in this grouping process. BOT-2 was used to detect the motor proficiency levels of the group.

Support was also received from special training experts within this concept. The aim of these tests is to determine the contribution of regular sports training on personal development in individuals with autism, as a result of the statistical analysis of the preliminary-final test data obtained.

If individuals with autism were to be compared with healthy individuals in particular, problems were seen in individuals diagnosed with autism related to balance, postural stability, walking, joint flexibility, and movement speed (Borazanc1, 2003; Özbey, 2009). 
In our study, it was recorded that the final test result of running speed and agility of the EGA's BOT-2 was higher than the preliminary test result, and a statistically significant difference was seen between them. In a similar study conducted by Yılmaz, Yanardağ, Birkan, and Bumin (2004), it was stated that hydrotherapy was applied on a nine years old boy for 60 minutes a day and three days a week for 10 weeks, and running speed and agility parameters of the boy increased as a result of the study.

Yanardağ (2007) evaluated eight boys with autism aged 5-7 with BOT-2. They applied this exercise work in land and pool environment for 40 minutes a day and three days a week for 12 weeks. In this study, it was seen that the land group increased from the pre-exercise score of 0.75 to 1.75 points following exercise in balance test. In our study, while the pre-exercise score was 1.16 points, it was seen to have increased to 1.64 points following exercise according to balance test results. In our study, while the balance test pre-exercise score was 6.32 points, it was seen to have increased to 8.83 points following exercise. In light of the information provided above, similar literature studies provided as example show parallelism with each other.

According to Orhan (2014) positive changes occurred in socialization level of the individual with autism following the movement training applied. Positive results were detected in level of making eye contact in particular, and this shows parallelism with the changes of this research.

Ghaziuddin and Butler (1998) evaluated the motor functions of nine children displayed high function as well as 11 children with Asperger Syndrome with a mean age of 13 through Bruininks-Oseretsky Test of gross motor. At the end of the study, it was stated that problems were observed in both groups in revealing running speed, balance, bilateral coordination, limb strength, upper limb coordination, visual-motor control, and upper limb speed and dexterity. Ghaziuddin and Butler support the study we conducted (Tekin \& K1rcaali-İftar, 2001).

Corbett and Constantine (2006) used the visual and auditory continuous performance test to evaluate healthy children and children with autism and hyperactive attention deficit. As a result of this test, it was stated that children with autism were disadvantaged compared to healthy children with hyperactive attention deficit in terms of visual and auditory attention and rapid movement skills.

Y1lmaz, Yanardağ, Birkan, and Bumin (2004) stated that exercise programs must concentrate on basic motor skills, individual games and sports, and developmental activities to increase physical activity, due to the fact that children with autism had weak motor skills in general.

Piek and Dyck (2004) thought that exercises conforming to development levels must be integrated into daily lives of children with behavioural problem. They stated that such physical activities must include movements which would particularly improve basic locomotor, balance, and physical proficiency.

In light of this information, a statistically significant increase, compared to preliminary tests, was observed in all tests following exercise training, as a result of the comparison of preliminary-final test values of gross motor proficiencies (BOT-2) tests of the handicapped group with autism, including running speed and agility, standing on preferred foot on balance beam, standing on balance beam with toe and heel contact, simultaneous tapping of foot and hand fingers in the same direction, simultaneous tapping of foot and hand fingers in different directions, and standing broad jump.

As a result of research, it was observed and stated by trainers and parents of the children with autism that, while the exercise program applied provided positive developments to the motor performance rates of phenomenon, they also provided benefit in increase of the interaction of the children with autism with tools-equipment around them, with their special training experts during one-on-one trainings, and their trainers as well as parents. 


\section{References}

American Psychiatric Association (APA). (2000). Diagnostic and statistical manual of mental disorders-fourth edition (Text revision). Washington, D.C.: American Psychiatric Association.

Aydin, A. (2013). Target of education in children with autism: A better autistic or a more adaptable individual? US-China Education Review B, 3(7), 548-556.

Berninger, V. W., \& Rutberg, J. (1992). Relationship of finger function to beginning writing: Application to diagnosis of writing disabilities. Developmental Medicine and Child Neurology, 34(3), 198-215.

Borazanc1- Persson, S. (2003). AQ autistic intelligence and levels (19-20). Ankara: Sistem Publisher.

Bruininks, R. H. (2005). Bruininks-Oseretsky Test of motor proficiency (BOT-2). Minneapolis, M.N.: Pearson Assessment.

Crawford, S., MacDonncha, C., \& Smyth, P. J. (2013). Examining fundamental movement skills and social responsiveness of children with autism following a randomized physical activity intervention. US-China Education Review B, 3(8), 593-602.

Corbett, B. A., \& Constantine, L. J. (2006). Autism and attention deficit hyperactivity disorder: Assessing attention and response control with the integrated visual and auditory continuous performance test. Child Neuropsychology, 12(4-5), 335-348.

Düger, T., Bumin, G., Uyanık, M., Akı, E., \& Kayıhan, H. (1999). The assessment of Bruininks-Oseretsky Test of motor proficiency in children. Pediatric Rehabilitation, 3, 25-131.

Eichstaedt, C. B., \& Lavay, B. W. (1992). Physical activity for individuals with mental retardation. Champaign, I.L.: Human Kinetics.

Filipek, P. A., Accardo, P. J., Baranek, G. T., Cook Jr, E. H., Dawson, G., Gordon, B., ..., \& Minshew, N. J. (1999). The screening and diagnosis of autistic spectrum disorders. Journal of Autism and Developmental Disorders, 29(6), 439-484.

Ghaziuddin, M., \& Butler, E. (1998). Clumsiness in autism and Asperger Syndrome. Journal of Intellectual Disability Research, 42, 43-48.

Green, D., Charman, T., Pickles, A., Chandler, S., Loucas, T., \& Simonoff, E. (2008). Impairment in movement skills of children with autistic spectrum disorders. Developmental Medicine and Child Neurology, 51, 311-316.

Güneş, A. (2005). Autism and education of autistic children. İzmir: İlyaPublisher.

Haywood, K. M., \& Getchell, N. (2005). Life span motor development. USA: Human Kinetics, 4, 326.

Landa, R. (2007). Early communication development and intervention for children with autism. Mental Retardation and Developmental Disabilities Research Reviews, 13(1), 16-25.

Lang, R., Koegel, L. K., Ashbaugh, K., Regester, A., Ence, W., \& Smith, W. (2010). Physical exercise and individuals with autism spectrum disorders. Research in Autism Spectrum Disorders, 4, 565-576.

London, E. (2007). The role of the neurobiologist in redefining the diagnosis of autism. Brain Pathol, 17 (4), 408-411.

Mülazımoğlu-Ballı, Ö., \& Gürsoy, F. (2012). The study of validity and reliability of Bruininks-Oseretsky motor proficiency test for 5-6 year-old Turkish children. Hacettepe Journal of Sport Sciences, 23(3),104-118.

Noens, I., Van Berckelaer-Onnes, I., Verpoorten, R., \& Van Duijn, G. (2006). The ComFor: An instrument for the indication of augmentative communication in people with autism and intellectual disability. Journal of Intellectual Disability Research, 50 (9), 621-32.

Orhan, E. B. (2014). The effect of movement education on social skills in autism. Ankara: Gazi Üniversitesi Eğitim Bilimleri Enstitüsü.

Özbey, Ç. (2009). Special children and therapy methods. İstanbul: İnk1lap Publisher.

Pan, C. Y. (2008). Objectively measured physical activity between children with autism spectrum disorders and children without disabilities during inclusive recess settings in Taiwan. Journal of Autism and Developmental Disorders, 38, 1292-1301.

Piek, J. P., \& Dyck, M. J. (2004). Sensory motor deficits in children with developmental coordination disorder, attention deficit hyperactivity disorder and autistic disorder. Human Movement Science, 23, 475-488.

Tager-Flusberg, H., \& Caronna, E. (2007). Language disorders: Autism and other pervasive developmental disorders. Pediatric Clinics of North America, 54(3), 469-81.

Tekin, E., \& Kırcaali-İftar, G. (2001). Wrong teaching methods in special education. Ankara: Nobel Yayın Dağıtım.

Todd, T., \& Reid, G. (2006). Increasing physical activity in individuals with autism. Focus on Autism and Other Developmental Disabilities, 21, 167-176.

Volkmar, F., Chawarska, K., \& Klin, A. (2005). Autism in infancy and early child hood. Annuel Review of Psychol, 56, 315-36.

Williams, D. L., Goldstein, G., \& Minshew, N. J. (2006). Neuropsychologic functioning in children with autism: Further evidence for disordered complex information-processing. Child Neuropsychol, 12 (4-5), 279-98. 
Wolery, M., Bailey, D. B., \& Sugai, G. M. (1988). Effective teaching: Principals and procedures of applied behavioral analysis with exceptional students. Boston: Allyn \& Bacon.

Yanardağ, M. (2007). The effects of different exercise practices on motor performance and stereotypic behavior in autistic children (Ph.D. thesis, Hacettepe University, 2007).

Yılmaz, İ., Yanardağ, M., Birkan, B., \& Bumin, G. (2004). Effects of swimming training on physical fitness and water orientation in autism. Pediatrics International, 46, 624-626. 